\section{Efisiensi Pelat Beton dengan Bekisting dan Tulangan Konvensional menjadi Floordeck dan Tulangan Wiremesh}

\section{Hari Afriyono}

Konsultan Teknik Bidang Konstruksi dan Industri Nasional, Indonesia

\section{$\bowtie \quad$ afriono.81@gmail.com}

Pelat lantai beton selama ini masih banyak yang dikerjakan secara konvensional, yaitu cara pengerjaan yang masih menggunakan multipleks sebagai bekesting dan besi beton sebagai tulangannya yang dirakit secara manual di tempat. Sistem ini diperharui dengan sistem yang menggunakan pelat baja (floordeck) sebagai bekesting dan wiremesh sebagai tulangan. Artikel ini membahas efesiensi pelat beton yang dihasilkan jika mengganti metode bekisting dan tulangan konvensional dengan floordeck dan wiremesh. Analisa dilakukan dengan menghitung volume masing-masing metode dan kemudian menghitung biayanya. Harga yang digunakan berdasarkan data sekunder dari harga satuan dan penawaran dari pabrik. Hasil analisa ditemukan bahwa volume beton dapat dihemat antara $15 \%-25 \%$, tulangan beton lapisan bawah dapat direduksi sampai $100 \%$, sedangkan biaya perancah dapat dikurangi hingga $1 / 3$ dari keperluan pemakaian dengan cara konvensional.

Kata kunci: bekisting, floordeck, wiremesh, efesiensi

Diajukan: 20 Juli 2019

Direvisi: 22 Juli 2019

Diterima: 25 Juli 2019

Dipublikasikan online: 25 Juli 2019

\section{Pendahuluan}

Penggunaan bekisting semi modern sudah mulai berkembang. Bekisting yang umumnya terbuat dari kayu dirubah menjadi baja sehingga biaya menjadi lebih efisien (Wijaya dkk, 2012). Hanya saja metode ini masih menggunakan kayu dan perancah untuk lantai. Oleh karena itu, perlu model lain untuk lantai misalnya penggunaan floordeck.

Floordeck adalah bahan galvanis yang dibentuk menyerupai "seng gelombang" tapi tidak berfungsi sebagai material penutup atap. Floordeck adalah material pelapis bawah cor pelat lantai beton sebagai penganti bekisting kayu (multipleks). Floordeck juga sekaligus didesain untuk mengkonversi penggunaan besaran diameter besi dan mengkonversi ketebalan cor beton. Sistem tekuk (gelombang Pelat) di desain dapat membantu kekuatan struktur beton cor Pelat lantai (Abdullah dan Easterling, 2007; Fanaie dan Rajaeian, 2018).

Pelat floordeck jika digunakan sebagai pengganti bekisting maka apabila cor Pelat beton lantai sudah mengering (usia kering beton 28 hari) tidak perlu dilepas karena sudah menjadi satu kesatuan sebagai unsur kekuatan beton. Jika menggunakan bekisting kayu (multipleks) maka akan membutuhkan tiang-tiang dan balok penyangga (perancah/steiger) yang banyak. Hasil cor beton juga akan lebih rapi dan terhindar dari keropos yang diakibat oleh bekisting bocor.

Pemakaian floordeck juga dapat mengurangi waktu dan tenaga dalam pemasangannya dibanding bekisting kayu (Multipleks). Floordeck dapat mengurangi volume cor beton $15 \%$ sampai $25 \%$ dan mereduksi jumlah diameter besi tulangan cor beton karena sebagian luas tulangan tarik perlu akan dikonversi dengan pemakain Pelat bondek (Naray, 2015). Waktu akan lebih cepat lagi jika pembesian (konvensional) diganti dengan besi wiremesh.

Floordeck dapat digunakan dengan 2 (dua) cara, yaitu sistem balok lantai dicor terlebih dahulu lalu bondek dipasang di atasnya dan kemudian lantai di cor. Atau, cara lain yaitu balok lantai dicor secara bersamaan dengan pelat lantai beton. Bangunan-bangunan yang menggunakan aplikasi floordeck langit-langit bisa saja tidak ditutup plafon atau kondisi terekspos, dilakukan finishing cat atau dibiarkan apa adanya karena Pelat floordeck tidak berkarat (mengandung galvanis). Begitu juga dengan bangunan konstruksi baja, lantai akan sangat cocok jika menggunakan aplikasi pelat floordeck ini, cepat dan hasil yang lebih rapi, serta langsung dapat difinishing dengan cat di bawahnya bila diinginkan.

Kekurangan dari Pelat floordeck adalah tidak mudah dipotong, oleh sebab itu ketika akan diaplikasikan di lapangan sebaiknya diukur dengan tepat kebutuhan tiap panjangnya, kemudian diadakan dalam bentuk/modul potongan-potongan yang siap pakai.

Pelat Floordeck dalam pemasangannya membutuhkan alat bantu as listrik untuk penyambungan antar masing-masing lembaran pelat agar tidak terjadi slip saat tertarik. Pada pemasangan Pelat floordeck dibutuhkan pekerja/tukang yang telah berpengalaman, sehingga tidak semua tukang mampu memasangnya.

Floordeck tidak cocok diaplikasikan pada Pelat lantai cor beton area tepi/tidak ditopang balok, seperti; Pelat

Cara mensitasi artikel ini:

Afriyono, H (2019) Efisiensi Pelat Beton dengan Bekisting dan Tulangan Konvensional menjadi Floordeck dan Tulangan Wiremesh. Buletin Profesi Insinyur 2(1) 036-040 
kantilever dan Pelat kanopi. Pelat floordeck tidak dapat disambung, oleh karena itu akhir potongan/tepi Pelat floordeck harus terletak tepat di atas balok lantai.

Ukuran Pelat floordeck bervariasi mulai dari ketebalan $0,65 \mathrm{~mm}, 0,75 \mathrm{~mm}$ dan $1 \mathrm{~mm}$, sedangkan lebar dari 0,6-1,0 meter dan panjang maksimum 12 meter. Dengan cukup banyaknya varin yang disediakan maka penggunaan material ini sangat efektif dan efisien. Artikel ini akan membahas mengenai evaluasi penggunaan lantai beton konvensional yaitu dengan bekisting dan pembesian biasa dibandingkan dengan penggunaan floordeck dan wiremesh dalam hal biaya.

\section{Metode}

Analisa penggantian sistem Pelat beton bekesting konvensional dengan tulangan besi beton biasa menjadi sistem bekesting Pelat baja galvanis (floordeck) dengan tulangan wiremesh sangat mudah dilakukan.

Yang pertama adalah menentukan beban hidup selama operasional konstruksi. Yang kedua adalah menentukan tebal rencana pelat beton dengan dilanjutkan pemilihan tebal Pelat floordeck. Selanjutnya dipilih sistim shoring steiger, berapa propping rows yang diperlukan, serta terakhir adalah penentuan tulangan negatif dari wiremesh sesuai table yang tersedia. Analisa struktur akibat penggantian ini tidak dibahas dalam artkel ini.

Tebal pelat beton perlu adalah tebal pelat beton gross yang diukur dari atas pelat hingga sisi terbawah pelat, dan biasanya lebih tipis $1,0-2,0 \mathrm{~cm}$ dari tebal palat beton konvensional semula.
Langkah selanjutnya adalah menghitung volume dan biaya untuk masing-masing metode dengan menggunakan harga satuan yang tersedia di daerah yang ditinjau yaitu Banjarmasin.

\section{Hasil Analisa}

Pada bagian ini, contoh perhitungan floordeck diuraikan agar para insinyur dapat langsung memperkirakan efesiensi yang didapatkan jika menggunakan metode ini. Tabel 1 dan 2 memperlihatkan masing-masing maximum span formwork design dan composite slab design for union floordeck (PT Union Metal, 2018).

Diketahui dalam suatu pekerjaan cor Pelat beton lantai tipe single span, beban hidup operasional yang bekerja sebesar $400 \mathrm{~kg} / \mathrm{m}^{2}$, ukuran Pelat (netto) 3,00m x 6,00 m dengan tebal cor $12 \mathrm{~cm}$ dan mutu beton $\mathrm{K}-200$. Pada Pelat tersebut didapat tulangan utama d.12-150 dan tulangan pembagi d.8-200 dipasang rangkap.

Pelat tersebut akan di konversi sistem struktur dan pelaksanaanya dengan menggunakan bekesting Pelat floordeck serta tulangan wiremesh.

Dari table brosur floordeck yang tersedia didapat hasil sebagai berikut :

1. Dipakai tipe floordeck dengan ketebalan Pelat BMT. $0,75 \mathrm{~mm}$ dan tebal cor $12 \mathrm{~cm}$, dengan mutu beton sama yaitu K-200

2. Tulangan utama dan susut memakai wiremesh tipe M8

3. Perancah satu baris dipasang di sepanjang tengah bentang .

Tabel 1 Maximum Span Formwork Design for Union Floor Deck II@ BMT 0.75 (mm).

\begin{tabular}{|c|c|c|c|c|c|c|}
\hline \multirow{2}{*}{$\begin{array}{c}\text { Proping } \\
\text { Rows }\end{array}$} & \multicolumn{2}{|c|}{$100 \mathrm{~mm}$ Slab } & \multicolumn{2}{c|}{$120 \mathrm{~mm}$ Slab } & \multicolumn{2}{c|}{$140 \mathrm{~mm}$ Slab } \\
\cline { 2 - 7 } & Single & Continous & Single & Continous & Single & Continous \\
\cline { 2 - 7 } & $(\mathrm{mm})$ & $(\mathrm{mm})$ & $(\mathrm{mm})$ & $(\mathrm{mm})$ & $(\mathrm{mm})$ & $(\mathrm{mm})$ \\
\hline 0 & 2100 & 2450 & 1950 & 2450 & 1850 & 2350 \\
\hline 1 & 3250 & 4000 & 3700 & 4800 & 4100 & 4450 \\
\hline 2 & 3250 & 4000 & 3700 & 4900 & 4100 & 5600 \\
\hline
\end{tabular}

Tabel 2 Composite Slab Design for Union Floor Deck IIC BMT 0.75 mm and $120 \mathrm{~mm}$ Slab

\begin{tabular}{|c|c|c|c|c|c|}
\hline \multirow{2}{*}{ Items } & \multicolumn{4}{|c|}{ Live Load } & \multirow{2}{*}{$\begin{array}{c}\text { Shringkage } \\
\text { Reinf. }\end{array}$} \\
\hline & $150 \mathrm{kPa}$ & $200 \mathrm{kPa}$ & $300 \mathrm{kPa}$ & $400 \mathrm{kPa}$ & \\
\hline Max. Single Span, mm & 3700 & 3600 & 3400 & 3250 & \multirow{5}{*}{$\begin{array}{c}\text { Internal } \\
\text { Condition } \\
\text { M6 } \\
\text { External } \\
\text { Condition } \\
\text { M8 }\end{array}$} \\
\hline Max. End Span,mm & 4300 & 4200 & 4000 & 3850 & \\
\hline Strenght Reinf. & $\begin{array}{c}\phi 12-200 \\
(\mathrm{M} 8)\end{array}$ & $\begin{array}{c}\varnothing 12-200 \\
\text { (M8) }\end{array}$ & $\begin{array}{c}\varnothing 12-200 \\
(\mathrm{M} 8)\end{array}$ & $\begin{array}{c}\varnothing 12-200 \\
\text { (M8) }\end{array}$ & \\
\hline Max. Interior Span, mm & 4900 & 4800 & 4800 & 4800 & \\
\hline Strenght Reinf. & $\begin{array}{c}\varnothing 12-200 \\
(\mathrm{M} 8)\end{array}$ & $\begin{array}{c}\phi 12-200 \\
\text { (M8) }\end{array}$ & $\begin{array}{c}\varnothing 16-200 \\
\text { (M10) }\end{array}$ & $\begin{array}{c}\varnothing 16-200 \\
\text { (M10) }\end{array}$ & \\
\hline
\end{tabular}

Rincian volume pekerjaan dapat dihitung sebagai berikut :

\section{Pelat beton sistem konvensional}

1. Volume beton $\mathrm{K}-200$ 
$=0,12 \times 3,00 \times 6,00=2,16 \mathrm{~m}^{3}$

2. Volume besi

$$
\begin{aligned}
\text { d. } 12 & =3,00 \times 600 / 15 \times 1 \times 0,887 \\
& =106,44 \mathrm{~kg}(20 \text { batang }) \\
\text { d. } 8 & =6,00 \times 300 / 20 \times 1 \times 0,39 \\
& =35.10 \mathrm{~kg}(7,5 \text { batang }) \\
\text { Total } & =141,54 \mathrm{~kg}
\end{aligned}
$$

3. Volume bekesting

$$
=3,00 \times 6,00=18,00 \mathrm{~m}^{2}
$$

4. Volume perancah

$$
=3,00 \times 6,00=18,00 \mathrm{~m}^{2}
$$

Pelat beton dengan bekesting floordeck dan tulangan wiremesh

1. Volume beton $\mathrm{K}-200$

$$
\begin{aligned}
& =0,11 \times 3,00 \times 6,00-((0,032+0,014) / 2 \\
& \times 0,054 \times 5 \times 3,00 \times 6,00) \\
& =1,98-0,112=1,87 \mathrm{~m}^{3}
\end{aligned}
$$

2. Volume wiremesh $\mathrm{M} 8$

$$
\begin{aligned}
& =3,00 \times 6,00 /(2,10 \times 5,40) \\
& =1,60 \mathrm{lbr}
\end{aligned}
$$

3. Volume floordeck BMT. 0,75 mm

$$
=3,00 \times 6,00=18,00 \mathrm{~m}^{2}
$$

4. Volume perancah

$$
=1,00 \times 6,00=6,00 \mathrm{~m}^{2}
$$

\section{Perhitungan biaya pekerjaan}

Biaya perkerjaan untuk kedua metode yaitu pelat beton konvensional dan pelat beton dengan bekisting floordesk dan tulangan wiremesh dihitung menggunakan data-data pada Tabel 3-10.

\section{Pelat beton sistem konvensional}

1. Pekerjaan beton $\mathrm{K}-200$
a. Material beton
2,16 m3 x 820.000,- = 1.771.200,-
b. Upah cor
18,00 m2 x 73.000,- = 1.314.000,-

2. Pekerjaan pembesian

a. Material besi

d. $12=10$ btg $\times 91.500,-=915.000,-$ d. $8=7,5$ btg $\times 41.000,-=307.500,-$

b. Upah pembesian $18,00 \times 20.000,-=380.000,-$

3. Pekerjaan bekesting

a. Material bekesting

Multipleks $12 \mathrm{~mm}$

$=18 \mathrm{~m} 2 /(1,22 \times 2,44) \mathrm{m} 2 \times 144.000$,-

$=870.750$,-

Pemakaian 2X = 435.375,-

Kayu usuk $4 / 6$ borneo

$=18 \mathrm{~m} 2 \times 6 \mathrm{~m}^{\prime} \times 30.500,-=3.294 .000$,-

Pemakaian $2 X=1.647 .000$,-

b. Upah bekesing

$=18,00 \mathrm{~m} 2 \times(55.000-15.000)$

$=720.000$,-

4. Pekerjaan perancah

a. Material perancah

Dolken dia. 6-8 cm

\author{
$=18,00 \mathrm{~m} 2 \times 12 \mathrm{btg} \times 16.000,-$ \\ $=3.456 .000,-$ \\ Pemakaian $2 X=1.728 .000$,- \\ b. Upah perancah \\ $=18,00 \mathrm{~m} 2 \times 15.000,-=270.000,-$ \\ Total biaya = Rp. 9.488.075,-
}

\section{Pelat beton dengan bekesting floordeck dan tulangan} wiremesh

1. Pekerjaan beton K-200
a. Material beton $1,87 \mathrm{m3}$ x 820.000,- = 1.533.400,-
b. Upah cor $18,00 \mathrm{~m} 2 \times 73.000,-=1.314 .000,-$

2. Pekerjaan pembesian (wiremesh)
a. Material wire mesh $=1.60 \mathrm{lbr} \times 550.150,-=880.250$,-
b. Upah pasang $18,00 \times 6.000,-=108.000,-$

3. Pekerjaan floordeck

a. Material floordeck BMT. 0,75 mm $=18,00 \mathrm{~m} 2$ x 104.000,-= 1.872.000.-

b. Upah pasang $=18.00 \times 20.000,-=360.000,-$

4. Pekerjaan perancah

a. Material perancah

Dolken dia. $6-8 \mathrm{~cm}$

$=6,00 \mathrm{~m} 2 \times 12 \mathrm{btg} \times 16.000$,-

$=1.152 .000$,-

Pemakaian 2X $=576.000$,-

b. Upah perancah = 6,00 m2 x 15.000,- = 90.000,-

Total biaya $=$ Rp. 6.733.650,-

Tabel 3 Harga Multipleks /Teakwood

\begin{tabular}{|l|c|c|}
\hline Spesifikasi Multipleks & Satuan & Harga (Rp.) \\
\hline $\begin{array}{l}\text { Multipleks } 12 \mathrm{~mm} \\
122 \times 244\end{array}$ & Lembar & $144.000,-$ \\
\hline $\begin{array}{l}\text { Multipleks } 15 \mathrm{~mm} \\
122 \times 244\end{array}$ & Lembar & $179.000,-$ \\
\hline $\begin{array}{l}\text { Multipleks } 18 \mathrm{~mm} \\
122 \times 244\end{array}$ & Lembar & $205.000,-$ \\
\hline $\begin{array}{l}\text { Blacboard } 18 \mathrm{~mm} \\
122 \times 244\end{array}$ & Lembar & $220.000,-$ \\
\hline
\end{tabular}

Tabel 4 Harga Kayu Usuk Bekesting

\begin{tabular}{|l|c|c|}
\hline Jenis Kayu & Satuan & Harga (Rp.) \\
\hline $\begin{array}{l}\text { Kayu Usuk Meranti } \\
5 \times 7 \times 400 \mathrm{~cm}\end{array}$ & Batang & $41.500,-$ \\
\hline $\begin{array}{l}\text { Kayu Usuk Borneo } \\
4 \times 6 \times 400 \mathrm{~cm}\end{array}$ & Batang & $30.500,-$ \\
\hline $\begin{array}{l}\text { Kayu Usuk Borneo } \\
5 \times 7 \times 400 \mathrm{~cm}\end{array}$ & Batang & $45.500,-$ \\
\hline $\begin{array}{l}\text { Kayu Usuk Kamper } \\
4 \times 6 \times 400 \mathrm{~cm}\end{array}$ & Batang & $54.500,-$ \\
\hline
\end{tabular}

Tabel 5 Harga Kayu Dolken/Galam Perancah

\begin{tabular}{|c|c|c|}
\hline Ukuran Galam & Satuan & Harga (Rp.) \\
\hline$\varnothing .4-6 \mathrm{~cm} \times$ L. $4 \mathrm{~m}$ & Batang & $8.000,-$ \\
\hline$\varnothing .6-8 \mathrm{~cm} \times$ L. $4 \mathrm{~m}$ & Batang & $16.000,-$ \\
\hline
\end{tabular}




\begin{tabular}{|l|l|l|}
\hline$\varnothing .8-10 \mathrm{~cm} \times$ L. $4 \mathrm{~m}$ & Batang & $25.000,-$ \\
\hline$\varnothing .10-12 \mathrm{~cm} \times$ L. $4 \mathrm{~m}$ & Batang & $35.000,-$ \\
\hline
\end{tabular}

Tabel 6 Harga Wiremesh

\begin{tabular}{|l|c|c|}
\hline \multicolumn{1}{|c|}{ Spesifikasi Wiremesh } & Satuan & Harga (Rp.) \\
\hline $\mathrm{M} 7 ; 2,1 \mathrm{~m} \times 5,4 \mathrm{~m}$ & Lembar & $425.150,-$ \\
\hline $\mathrm{M} 8 ; 2,1 \mathrm{~m} \times 5,4 \mathrm{~m}$ & Lembar & $590.150,-$ \\
\hline $\mathrm{M} 9 ; 2,1 \mathrm{~m} \times 5,4 \mathrm{~m}$ & Lembar & $725.150,-$ \\
\hline $\mathrm{M} 10 ; 2,1 \mathrm{~m} \times 5,4 \mathrm{~m}$ & Lembar & $890.150,-$ \\
\hline
\end{tabular}

Tabel 7 Harga Floordeck (PT Alsun Suksesindo, 2018)

\begin{tabular}{|l|c|c|}
\hline \multicolumn{1}{|c|}{ Spesifikasi Floordeck } & Satuan & Harga (Rp.) \\
\hline FD t. 0,70 mm - L. $1000 \mathrm{~mm}$ & $\mathrm{~m}$ & $100.000,-$ \\
\hline FD t. 0,75 mm - L. $1000 \mathrm{~mm}$ & $\mathrm{~m}$ & $104.000,-$ \\
\hline Sakura DX $75-$ L. $1000 \mathrm{~mm}$ & $\mathrm{~m}$ & $125.000,-$ \\
\hline FD t. 0,65 mm - L. $1000 \mathrm{~mm}$ & $\mathrm{~m}$ & $93.000,-$ \\
\hline
\end{tabular}

Tabel 8 Harga Besi Beton

\begin{tabular}{|c|c|r|}
\hline Spesifikasi Besi & Satuan & Harga (Rp.) \\
\hline$\varnothing .8 \mathrm{~mm}-$ L. $12 \mathrm{~m}$ & Batang & $38.000,-\mathrm{s} / \mathrm{d} \mathrm{44.000,-}$ \\
\hline$\varnothing .10 \mathrm{~mm}-$ L. $12 \mathrm{~m}$ & Batang & $59.000,-\mathrm{s} / \mathrm{d} 65.000,-$ \\
\hline$\varnothing .12 \mathrm{~mm}$ - L. $12 \mathrm{~m}$ & Batang & $84.000,-$ s/d 99.000,- \\
\hline$\varnothing .16 \mathrm{~mm}-$ L. $12 \mathrm{~m}$ & Batang & $140.000,-\mathrm{s} / \mathrm{d} 168.000,-$ \\
\hline
\end{tabular}

Tabel 9 Harga Upah/Borongan Pekerjaan

\begin{tabular}{|l|c|r|}
\hline Jenis Pekerjaan & Satuan & Harga (Rp.) \\
\hline Cor Pelat Dak & $\mathrm{m}^{2}$ & $73.000,-$ \\
\hline Pembesian Pelat Dak & $\mathrm{m}^{2}$ & $20.000,-$ \\
\hline Bekesting + Perancah Pelat Dak & $\mathrm{m}^{2}$ & $55.000,-$ \\
\hline Perancah Pelat Dak & $\mathrm{m}^{2}$ & $15.000,-$ \\
\hline Pasang Wiremesh & $\mathrm{m}^{2}$ & $6.000,-$ \\
\hline Pasang Floordeck & $\mathrm{m}^{2}$ & $20.000,-$ \\
\hline
\end{tabular}

Tabel 10 Harga Beton K.200

\begin{tabular}{|l|l|l|}
\hline Truck Standar s/d $8 \mathrm{~m}^{3} /$ rit & $\mathrm{m}^{3}$ & $820.000,-$ \\
\hline Truck Mini s/d $4 \mathrm{~m}^{3} /$ rit & $\mathrm{m}^{3}$ & $1.170 .000,-$ \\
\hline
\end{tabular}

Untuk keadaan riil di lapangan, total biaya tersebut masih harus dikalikan $25 \%$ lagi untuk tambahan variabel biaya; faktor pembesaran volume $10 \%$, biaya material penunjang dan peralatan kerja $7,5 \%$, biaya angkut material dan overhead $5 \%$, serta biaya manajemen proyek $2,5 \%$. Perbandingan total biaya antara penggunaan Pelat beton konvensional dengan floordeck dan tulangan wiremesh terlihat pada Gambar 1. Dimana secara umum terlihat bahwa metode dengan floordeck dapat menghemat biaya sampai $30 \%$. Hasil ini sesuai dengan analisa yang dilakukan oleh Wibawa, dkk (2017) untuk kasus sebuah gedung di Bali bahwa penggunaan floordeck dapat menghemat biaya sampai $38 \%$.

Cara mengaplikasikan floordeck adalah dengan mengatur arah ruas lipatan untuk bentang (jarak) antar balok terpendek, misalkan; bidang persegi ukuran $3 \mathrm{~m} \mathrm{x}$ $6 \mathrm{~m}$ maka dipakai potongan floordeck panjang @2,85m $x 1 \mathrm{~m}$ (lebar), dengan jumlah kurang lebih 10 lembar jika dipakai lebar lembaran 0,6 meter. Hasil pemasangan floordeck dan wiremesh, posisi floordeck terhadap balok, dan floordeck sebagai plafon ekspose masingmasing terlihat pada Gambar 2, Gambar 3, dan Gambar 4.

\section{Kesimpulan}

Dari hasil analisa perbandingan pekerjaan dan biaya dari dua metode yang dibahas, dapat disimpulkan beberapa hal sebagai berikut:

1. Volume material beton dengan sistem floordeck dapat dihemat sebesar $14 \%$, atau mendekati $15 \%$.

2. Pada pekerjaan bekesting dan pembesian, biaya dengan floordeck berkurang menjadi $73 \%$ dari sistem konvensional.

3. Untuk biaya perancah, biaya dengan floordeck berkurang drastis menjadi sekitar $33 \%$, atau $1 / 3$ dari biaya sistem konvensional.

4. Secara umum total biaya untuk sistem ini dapat dihemat sebesar $30 \%$, atau bisa ditekan hingga $70 \%$ dari biaya dengan sistem konvensional.

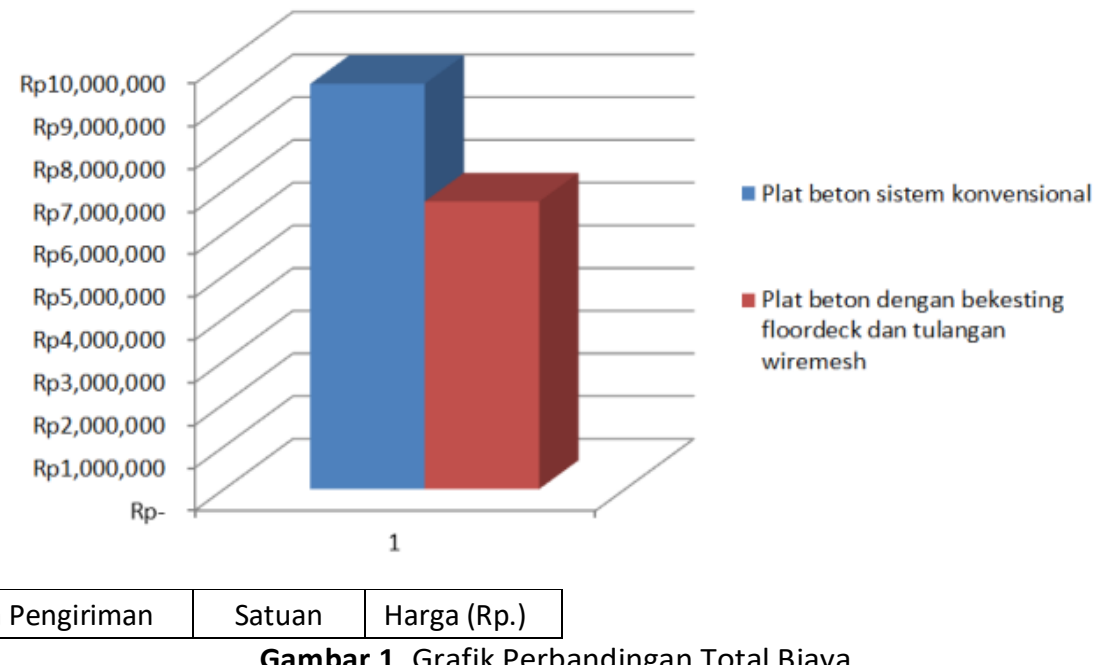

Gambar 1. Grafik Perbandingan Total Biaya 


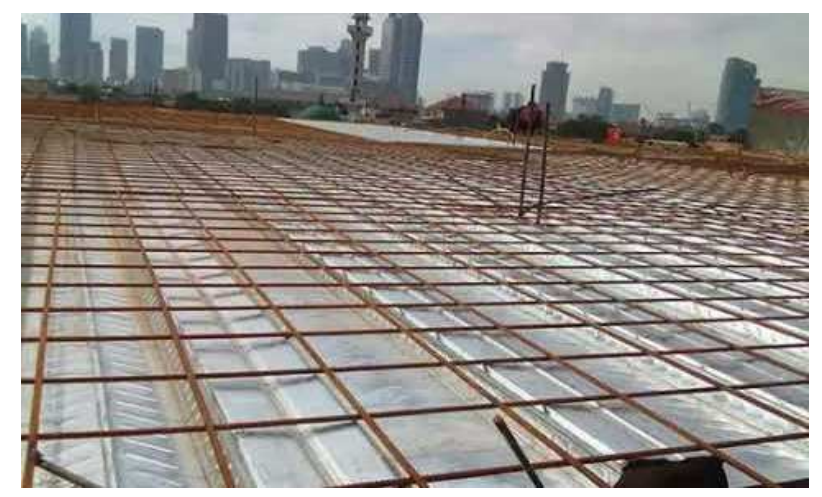

Gambar 2 Contoh Hasil Pemasangan Floordeck

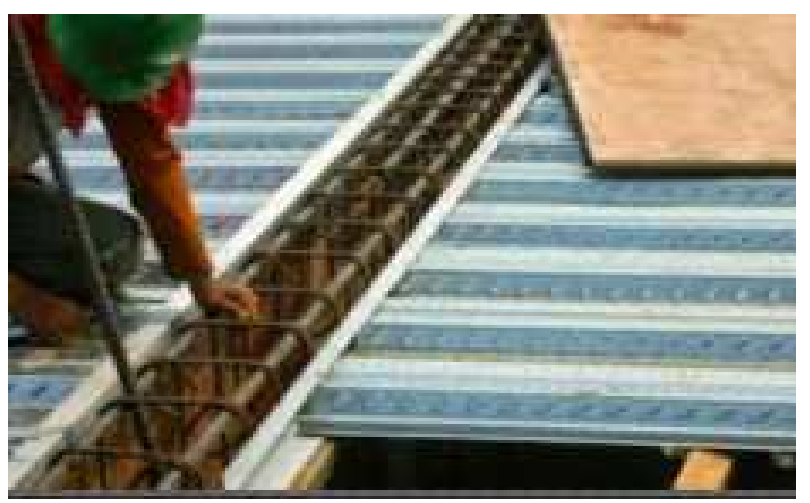

Gambar 3 Posisi Floordeck Terhadap Balok

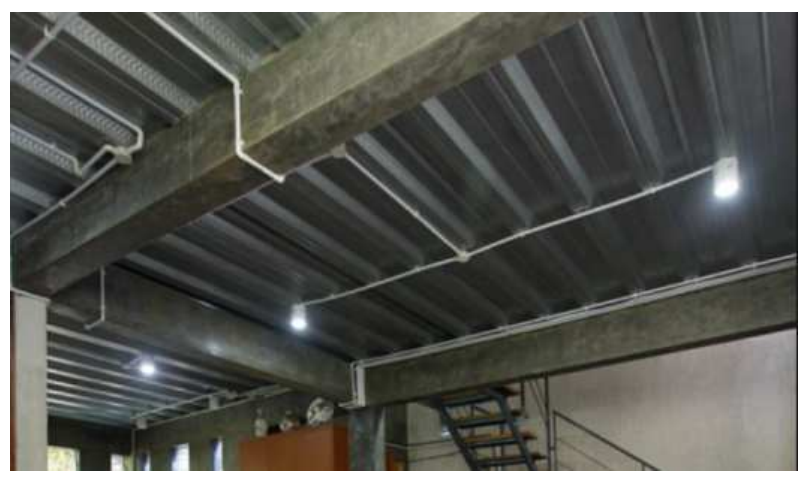

Gambar 5 Floordeck Sebagai Plafon Ekspos

\section{Referensi}

Abdullah, R. dan Easterling, W.S (2007) Determination of Composite Slab Strength Using a New Elemental Test Method. Journal of Structural Engineering 133(9): 1268-1277 DOI:10.1061/(ASCE)0733-9445(2007)133: $9(1268)$

Fanaei, N. dan Rajaeian, P (2018) Analytical Shape Optimization of Metal Deck with respect to Bending Capacity. Proceeding of $3^{\text {rd }}$ International Conference on Steel \& Structure.

Naray, F (2015) Analisa Perencanaan dan Pelaksanaan Pelat Bondek Sebagai Pengganti Tulangan Tarik Konstruksi Pelat Lantai Proyek Gedung Kuliah Terpadu Politeknik Negeri Manado. Jurnal Teknik Politeknik Negeri Manado.

PT. Union Metal (2018) Union Floor Deck W-1000 (Bondek) dan Wire Mesh. PT. Union Metal, Jakarta. http://www.unionmetal.co.id/page/steelstructure/post_content/155-Union-New-Floor-DeckW-1000.html

PT. Alsun Suksesindo (2018) Floordeck FD-600. PT. Alsun Suksesindo, Jakarta. https://steelindonesia.com

Wibawa, I.G.S, Wiguna, I. P. R S., Tapayasa, I.M., Santiana, I. M. A (2017) Perbandingan kebutuhan biaya pekerjaan pengecoran pelat lantai metode konvensional dengan metode floor deck studi kasus pada pembangunan proyek The Hattens Wines Bali. Jurnal Logic 17(1): 60-66.

Wijaya, I. B. A, Djakfar, L., Budio, S.P (2012) Studi perbandingan biaya bekesting semi modern dengan bekesting konvensional pada bangunan gedung. Jurnal Rekayasa Sipil 6(3) 237-243. 